\title{
GCU
}

Glasgow Caledonian

University

University for the Common Good

\section{Ventilator-associated pneumonia surveillance using two methods}

Craven, T.H.; Wojcik, G.; McCoubrey, J.; Brooks, O.; Grant, E.; Keating, S.; Reilly, Jacqui; Laurenson, I.F.; Kefala, K.; Walsh, T.S.

Published in:

Journal of Hospital Infection

DOI:

10.1016/j.jhin.2020.01.020

Publication date:

2020

Document Version

Author accepted manuscript

Link to publication in ResearchOnline

Citation for published version (Harvard):

Craven, TH, Wojcik, G, McCoubrey, J, Brooks, O, Grant, E, Keating, S, Reilly, J, Laurenson, IF, Kefala, K \& Walsh, TS 2020, 'Ventilator-associated pneumonia surveillance using two methods', Journal of Hospital Infection, vol. 104, no. 4, pp. 522-528. https://doi.org/10.1016/j.jhin.2020.01.020

\section{General rights}

Copyright and moral rights for the publications made accessible in the public portal are retained by the authors and/or other copyright owners and it is a condition of accessing publications that users recognise and abide by the legal requirements associated with these rights.

Take down policy

If you believe that this document breaches copyright please view our takedown policy at https://edshare.gcu.ac.uk/id/eprint/5179 for details of how to contact us. 


\section{Ventilator-associated pneumonia surveillance using two methods}

Thomas H. Craven ${ }^{1,2,4^{*}}$, Gosha Wojcik ${ }^{2}$, Jodie McCoubrey ${ }^{3}$, Odette Brooks ${ }^{4}$, Esther Grant ${ }^{5}$, Sean Keating ${ }^{2}$, Jacqui Reilly ${ }^{3}$, lan F. Laurenson ${ }^{4}$, Kallirroi Kefala ${ }^{1,2,4}$ and Timothy S. Walsh ${ }^{1,2,4^{* *}}$

${ }^{1}$ Centre for Inflammation Research, University of Edinburgh, Edinburgh, UK.

${ }^{2}$ Edinburgh Critical Care Research Group, University of Edinburgh, Edinburgh, UK.

${ }^{3}$ Health Protection Scotland, Glasgow, UK.

${ }^{4}$ Clinical Microbiology, NHS Lothian Infection Service, Royal Infirmary of Edinburgh, Edinburgh, UK.

${ }^{5}$ Western General Hospital, Edinburgh, UK.

* Corresponding author: Thomas.craven@ed.ac.uk

** Alternate author: Timothy.Walsh@ed.ac.uk

Short running title: VAP surveillance

Declarations of interest: none 


\begin{abstract}
Background

Ventilator-associated pneumonia surveillance is used as a quality indicator due to concerns that some cases may be preventable and may contribute to mortality. Various surveillance criteria exist for the purposes of national reporting, but a large scale direct comparison has not been conducted.
\end{abstract}

Methods

A prospective cohort study applied two routinely used surveillance criteria for ventilator-associated pneumonia from the European Centre for Disease Control and the American Centers for Disease Control to all patients admitted to two large general intensive care units. Diagnostic rates and concordance amongst diagnostic events were compared.

Findings

713 at-risk patients were identified during the study period. The European surveillance algorithm returned a rate of 4.6 cases of ventilator-associated pneumonia per 1,000 ventilation days ( $95 \%$ confidence interval 31-6.6) and the American surveillance system a rate of 5.4 (3.8-7.5). The concordance between diagnostic events was poor (Cohen's Kappa $0.127(-0.003$ to 0.256$))$

\title{
Conclusions
}

The algorithms yield similar rates, but the lack of event concordance reveals the absence of interalgorithm agreement for diagnosing ventilator-associated pneumonia, potentially undermining surveillance as an indicator of care quality.

Keywords

Ventilator-associated pneumonia, Infection surveillance, Mechanical ventilation, Critical care 


\section{Introduction}

Ventilator associated pneumonia (VAP) refers to inflammation of the lung parenchyma caused by an infectious agent acquired specifically as a result of invasive mechanical ventilation. Throughout the last few decades study investigators have not adopted a fixed set of criteria or a fixed at-risk definition and this has led to an inability to make direct comparisons across study sets. This may account for a wide variety in reported incidence, where rates vary between $4.0 \%$ and $28.8 \%$ [1-8].

Surveillance and reporting of VAP is often mandated by care quality agencies and remuneration bodies [9] because it is perceived to be a potentially preventable complication which may contribute to morbidity and mortality. However, substantial inter-observer variability has been documented [10] as has a lack of correlation with autopsy findings [11]. Requiring microbiological confirmation adds less strength to the diagnosis than might be expected [12] and commonly used techniques have poor sensitivity and specificity compared to pulmonary biopsy $[13,14]$. Nonetheless, surveillance has been performed internationally for many years, and if the same method is used, regardless of its weaknesses, it should follow that trends can be observed and benchmarking can occur. Attributable morbidity has been shown to increase when surveillance is suspended, although confusingly not due to increased VAP occurrence [15]. The subjective nature of VAP diagnosis has led to accusations of gaming, undertaken to reduce the locally reported VAP rate; many surveillance rates approach zero, in contrast to the studied rates [16]. Scotland and other European countries use the surveillance methods recommended by the European Centre for Disease Prevention and Control [17] which contain subjective criteria [18].

To address the problem of subjectivity and repeatability, the American Centers for Disease Control and Prevention (CDC) developed a surveillance for Ventilator Associated Events (VAE) with objective and potentially automatable criteria [19]. The CDC algorithm returns a hierarchical diagnosis from 
ventilator-associated complication (VAC) to infection related ventilator-associated complication (IVAC), and probable VAP [20]. The aim of this new CDC algorithm is to capture all episodes of deterioration on a ventilator (whatever the cause), facilitate surveillance that can be done objectively, electronically, and reproducibly [9], and is integral to their strategy to reduce ICU acquired infection [21].

The primary aim of this study was to compare the ECDC case definition for VAP with the CDC algorithm for VAP and with clinician suspected VAP (CS VAP). There have been few attempts to directly compare the surveillance algorithms. One UK study compared ECDC and CDC surveillance criteria returning dissimilar VAP rates and did not look specifically at concordance between algorithms [22]. One Serbian study found good concordance between algorithms [23]. We previously reported the initial analysis of the study presented herein, indicating poor concordance amongst individual VAP occurrences [24]. 
Methods

Setting

A prospective observational cohort study was carried out at two large adult (aged 16 or over) intensive care units located at the Royal Infirmary of Edinburgh and the Western General Hospital, Edinburgh. As a service evaluation ethical approval was not required. The data capture, storage and analysis plans were authorized by the Caldicott guardian.

\section{Data Collection}

Data were collated for patients admitted between $1^{\text {st }}$ June 2015 and $31^{\text {st }}$ May 2016 who were admitted for more than two calendar days (where one calendar day was defined as any whole or part period from $0000 \mathrm{hrs}$ to $0000 \mathrm{hrs}$ ). There is no consistent definition of the at-risk population for VAP amongst mechanically ventilated patients. To present comparisons across groups, we defined the at-risk population as those who received at least 2 calendar days of mechanical ventilation.

CDC VAP data: A team of research nurses received training and supervision in the collection of CDC pertinent information for all patients who were admitted for more than two calendar days (CD). CDC VAP was defined according to the CDC algorithm (January 2015, updated April 2015, see supplemental figure 1) which is based on the original publication by the working group [19].

ECDC VAP data: ECDC VAP was defined according ECDC criteria [17]. Routine VAP surveillance data using the ECDC case definition was collected by the ICU acquired infection surveillance team, according to their standard practice. This was a separate team that worked in isolation from the CDC VAP study team. ECDC VAP cases were classified into Pneumonia (PN) 1-5 according to characteristics of microbiological results related to the trigger clinical event (see supplemental table I). 
Clinician Suspected VAP (CS VAP) data: Information pertaining to new antibiotic prescriptions for suspected chest infection was also collected by the study team to identify CS VAP. CS VAP was defined as the initiation of a new antibiotic for suspected chest infection in a ventilated patient after $2 \mathrm{CD}$ of mechanical ventilation (MV) which was not a replacement, escalation, or de-escalation for a pre-existing antibiotic prescription. A summary of the three VAP definitions used in the study are shown in table I.

\title{
Modification to the CDC Algorithm
}

Microbiological sampling proceeded as part of routine care but due to subtle differences in the capability of the local microbiology services and the antibiotic uses we modified the CDC surveillance algorithm to ensure it could be delivered. Firstly, we added two commonly used antibiotics, amoxicillin and co-amoxiclav, to the qualifying antibiotic list. Secondly, we modified diagnosis by criterion 2 from purulent respiratory secretions ( $\geq 25$ neutrophils and $\leq 10$ squamous epithelial cells per low power field [Ipf, x100]) AND identification of organisms NOT meeting the quantitative or semi-quantitative thresholds to:

- For endotracheal aspirates: any mention of purulence and any report of bacterial or fungal culture (discounting commensal organisms specified in the CDC VAE Surveillance protocol e.g. Candida spp.).

- For broncho-alveolar lavage: any mention of purulence and positive culture NOT meeting the quantitative threshold.

The modification described here is not among the range of deviation options listed by the CDC but was necessary to accommodate local microbiology reporting practices.

\author{
Assessment of Ventilator-associated events \\ In addition to an assessment of ventilator-associated pneumonia we also performed for surveillance \\ of all hierarchical ventilator associated events as defined by the American CDC (supplemental figure
}


1, ventilator-associated condition (VAC), infection related ventilator-associated condition (IVAC)). We calculated the number of events where failure to collect microbiological samples was the cause of failure to progress through the hierarchy. Two intensive care specialists working independently performed an electronic case note review for each VAC/IVAC to determine to underlying cause of deterioration in oxygenation following a period of stability. Choices of True VAP, pulmonary oedema, atelectasis, deterioration in pre-existing condition, inadequate microbiological data to draw further conclusions, and other were permitted.

Analysis

VAP rates were calculated using the total number of ventilation days from the at-risk population and reported on a per patient and per event basis. Details of the statistical test to compare baseline characteristics are shown with the relevant figure. $\mathrm{P}<0.05$ was considered statistically significant. VAP concordance was determined on a per patient basis, presented in a $2 \times 2$ table and calculated using Cohen's Kappa (GraphPad online calculator, located at https://graphpad.com/quickcalcs/kappa1.cfm). No reference standard was available so positive and negative percent agreements were calculated. (PPA and NPA, analogous to sensitivity to specificity respectively if a perfect reference standard were available)[25]. 


\section{Results}

\section{Summary of enrolled cases}

During the period $1^{\text {st }}$ June 2015 and $31^{\text {st }}$ May 20161972 patients were admitted. A flow chart describing the breakdown of the admitted population is shown in figure 1 . Selected admission characteristics are shown in table II.

\section{Diagnosis of ventilator associated pneumonia}

The number of events and the associated VAP rates and proportions detected via the three methods are shown in table III. The two surveillance algorithms returned very similar rates. However, the CS VAP rate was approximately five times that returned by either algorithm, and nearly a quarter of patients who undergo at least two calendar days of mechanical ventilation receive a new antibiotic directed at VAP. The median ( $\pm \mathrm{IQR})$ number of calendar days to first diagnosis of event was 5 (4.07.0), 6 (3.8-7.0), and 5 (3.0-8.0) for CDC VAP, ECDC VAP, and CS VAP respectively. The baseline characteristics of each VAP cohort and the admission types are summarized in table IV.

\section{Microbiology of VAP}

Amongst 35 ECDC VAP identified, 20 (57.1\%) were confirmed microbiologically (PN1-4) and 15 (42.9\%) were classified as PN5 i.e. there was no supportive microbiological data and VAP was diagnosed clinically.

By definition, for a CDC VAP to be diagnosed, the appropriate respiratory microbiology samples must have been examined at or around the time of sustained deterioration in respiratory function and have met appropriate microbiological thresholds, so all cases have at least one associated microorganism. 
There were 150 patients who experienced 160 episodes of CS VAP. Microbiological samples were sent within five calendar days ( 2 days before and 2 days after) of the initiation of antibiotics in $34 / 150$ patients and $41 / 160$ (25.6\%) occasions. $27 / 150$ patients and $32 / 160$ cases were microbiologically confirmed. A table of causative organisms is shown in Supplemental table II.

Concordance between surveillance methods

In the absence of a true reference standard for VAP, the CDC surveillance algorithm was compared to the routinely used ECDC surveillance case definition for VAP. The concordance of at-risk patients with and without a VAP surveillance diagnosis according to the two surveillance methods is shown in table V. Positive VAP events from both surveillance algorithms which do not overlap in time remain concordant in this analysis.

We examined the concordance between CS VAP and each surveillance method (table VI). Due to the low contemporaneous sampling rate around the initiation of antibiotics we also examined the concordance between CS VAP where microbiology samples had been sent to the surveillance definitions (supplemental table III).

\section{Experience of VAE hierarchical diagnosis}

A summary of the incidence of VAEs is shown in table VII. Where a patient experiences more than one VAE at more than one hierarchical level they are collated into the highest experienced diagnostic group.

We examined the effect of the strict time window either side of the IVAC day (the first day of the sustained deterioration in oxygenation) during which positive microbiology samples must be 
obtained to diagnose a CDC VAP. Out of 38 IVACs, only 3 (7.9\%) would have progressed to CDC VAP had the IVAC window been extended to last for the duration of the trigger antibiotic course.

Of 38 IVACs however, only 19 (50.0\%) had appropriate samples taken within the 5-day window, meaning 19 patients could, under no circumstances, progress to CDC VAP. On 13/19 (68.4\%) of occasions, the opportunity to take an appropriate sample was missed, and on the remaining six occasions respiratory microbiology was available just prior to the start of the VAE window, making further respiratory sampling redundant. Of the thirteen occasions where sampling was missed, samples were taken after the 5-day window but during the trigger antibiotic course on 8 occasions, three of which were positive.

For each VAC/IVAC a summary of alternative diagnoses is given in Table VIII. The reviewers demonstrated moderate concordance for True VAP diagnosis (see supplemental table IV). 


\section{Discussion}

We applied the routinely used VAP surveillance methodology and the CDC VAP algorithm to twelve months' worth of admissions to two large general intensive care units. We found VAP rates that were similar to previously published research and service evaluations [26-31]. We found the surveillance rate of VAP to be very similar between the two surveillance algorithms. We describe the lack of concordance amongst patients who are diagnosed with VAP, regardless of timing of VAP diagnosis. Concordance between the two algorithms has not examined extensively in the literature since the introduction of the CDC hierarchical approach but at least one study has previously reported good concordance [23]. We previously reported the lack of concordance between individual VAP occurrences where overlap in time was required [24].

At first glance, the similar rates returned by each surveillance algorithm are reassuring and the surveillance output from either system will provide consistent data, if implemented properly. But the lack of concordance highlights a worrying problem with VAP surveillance and serious problem with VAP research in general. How can VAP rates be used to measure care quality when there is no inter-algorithm agreement on who does and who does not have VAP? If VAP rates established by surveillance do not accurately represent the clinical burden of VAP and incorrectly estimates the clinical problem, clinicians will be reluctant to use the data as means to drive improvement. The lack of an agreed and effective reference standard for VAP has constrained research in the area and using surveillance techniques as a reference standard should not be advocated.

The CS VAP rate was approximately 5 times the VAP rate identified through surveillance, and $21 \%$ of patients "at-risk" of VAP received treatment for VAP. Selecting CS VAP as the reference standard for VAP should not be advocated, as it is known that this rate overestimates VAP [32], and clinicians cannot rely on delayed microbiological confirmation or confutation to guide antibiotic use, which otherwise guides the surveillance algorithms. We found several VAEs did not progress towards CDC 
VAP event because of lack of appropriate microbiological sampling and we consider several cases of true VAP to be missed, and this may account for some of the lack of concordance.

In order to make comparisons across diagnostic groups we defined our own at-risk population. The CDC define the at-risk population as those who receive more than 2 calendar days of mechanical ventilation. The ECDC define their at-risk population as the occurrence of invasive ventilation at any point in the preceding 48 hours. We accepted a pragmatic and consistent risk criterion of mechanical ventilation for 2 consecutive calendar days. This practical solution may put the validity of the conclusions at risk, by overestimating the population at risk according to the CDC definition, and underestimating the population at risk according to the ECDC definition. Furthermore, we adapted the microbiological criteria issued by the $\mathrm{CDC}$ in order to accommodate local practices. Whilst most of our laboratory reporting was semi-quantitative, local and national practice for respiratory sample handling (especially non broncho-alveolar lavage) yields some qualitative reporting. Relying on qualitative data for some microbiological samples may add a level of subjectivity to an otherwise objective process.

\section{Conclusion}

It will be difficult to overcome the uncertainty around the surveillance of VAP without a robust and reproducible reference standard and consensus regarding the definition of the at-risk population. The CDC method offers the theoretical advantages of avoiding subjective chest $\mathrm{x}$-ray interpretation and potential for automaticity, but the results of this study indicate that at present does not offer any advantage in terms of VAP surveillance for the purpose of measuring VAP to drive improvement in Scotland.

\section{Funding}

This work was supported by The Scottish Government. 


\section{References}

[1] Rello J, Quintana E, Ausina V, Castella J, Luquin M, Net A, et al. Incidence, Etiology, and Outcome of Nosocomial Pneumonia in Mechanically Ventilated Patients. Chest 1991;100:439-44. doi:10.1378/chest.100.2.439.

[2] Kappstein I, Schulgen G, Beyer U, Geiger K, Schumacher M, Daschner FD. Prolongation of hospital stay and extra costs due to ventilator-associated pneumonia in an intensive care unit. Eur J Clin Microbiol Infect Dis 1992;11:504-8.

[3] Kollef MH. Ventilator-associated pneumonia. A multivariate analysis. JAMA 1993;270:196570.

[4] Cook DJ, Walter SD, Cook RJ, Griffith LE, Guyatt GH, Leasa D, et al. Incidence of and Risk Factors for Ventilator-Associated Pneumonia in Critically III Patients. Ann Intern Med 1998;129:433. doi:10.7326/0003-4819-129-6-199809150-00002.

[5] Rello J, Ollendorf DA, Oster G, Vera-Llonch M, Bellm L, Redman R, et al. Epidemiology and outcomes of ventilator-associated pneumonia in a large US database. Chest 2002;122:211521.

[6] Tejerina E, Frutos-Vivar F, Restrepo MI, Anzueto A, Abroug F, Palizas F, et al. Incidence, risk factors, and outcome of ventilator-associated pneumonia. J Crit Care 2006;21:56-65. doi:10.1016/j.jcrc.2005.08.005.

[7] Hyllienmark P, Gårdlund B, Persson J-O, Ekdahl K. Nosocomial pneumonia in the ICU: A prospective cohort study. Scand J Infect Dis 2007;39:676-82. doi:10.1080/00365540701225728.

[8] Skrupky LP, McConnell K, Dallas J, Kollef MH. A comparison of ventilator-associated pneumonia rates as identified according to the National Healthcare Safety Network and American College of Chest Physicians criteria. Crit Care Med 2012;40:281-4. doi:10.1097/CCM.0b013e31822d7913.

[9] Klompas M, Khan Y, Kleinman K, Evans RS, Lloyd JF, Stevenson K, et al. Multicenter Evaluation 
of a Novel Surveillance Paradigm for Complications of Mechanical Ventilation. PLoS One 2011;6:e18062. doi:10.1371/journal.pone.0018062.

[10] Fagon JY, Chastre J, Hance AJ, Domart Y, Trouillet JL, Gibert C. Evaluation of clinical judgment in the identification and treatment of nosocomial pneumonia in ventilated patients. Chest 1993;103:547-53.

[11] Tejerina E, Esteban A, Fernández-Segoviano P, Frutos-Vivar F, Aramburu J, Ballesteros D, et al. Accuracy of clinical definitions of ventilator-associated pneumonia: Comparison with autopsy findings. J Crit Care 2010;25:62-8. doi:10.1016/j.jcrc.2009.05.008.

[12] Morris AC, Kefala K, Simpson AJ, Wilkinson TS, Everingham K, Kerslake D, et al. Evaluation of the effect of diagnostic methodology on the reported incidence of ventilator-associated pneumonia. Thorax 2009;64:516-22. doi:10.1136/thx.2008.110239.

[13] Papazian L, Thomas P, Garbe L, Guignon I, Thirion X, Charrel J, et al. Bronchoscopic or blind sampling techniques for the diagnosis of ventilator-associated pneumonia. Am J Respir Crit Care Med 1995;152:1982-91. doi:10.1164/ajrccm.152.6.8520766.

[14] Marquette CH, Copin MC, Wallet F, Neviere R, Saulnier F, Mathieu D, et al. Diagnostic tests for pneumonia in ventilated patients: prospective evaluation of diagnostic accuracy using histology as a diagnostic gold standard. Am J Respir Crit Care Med 1995;151:1878-88. doi:10.1164/ajrccm.151.6.7767535.

[15] Bénet T, Allaouchiche B, Argaud L, Vanhems P. Impact of surveillance of hospital-acquired infections on the incidence of ventilator-associated pneumonia in intensive care units: a quasi-experimental study. Crit Care 2012;16:R161. doi:10.1186/cc11484.

[16] Klompas M. Is a ventilator-associated pneumonia rate of zero really possible? Curr Opin Infect Dis 2012;25:176-82. doi:10.1097/QCO.0b013e3283502437.

[17] Savey A, Lepape A, Palomar M, Agodi A, Hiesmayr M. Surveillance of healthcare-associated infections and prevention indicators in European intensive care units HAI-Net ICU protocol, version 2.2 n.d. doi:10.2900/833186. 
[18] Walsh TS, Morris AC, Simpson AJ. Ventilator associated pneumonia: can we ensure that a quality indicator does not become a game of chance? Br J Anaesth 2013;111:333-7. doi:10.1093/bja/aet131.

[19] Magill SS, Klompas M, Balk R, Burns SM, Deutschman CS, Diekema D, et al. Developing a new, national approach to surveillance for ventilator-associated events. Am J Crit Care 2013;22:469-73. doi:10.4037/ajcc2013893.

[20] Klompas M, Magill S, Robicsek A, Strymish JM, Kleinman K, Evans RS, et al. Objective surveillance definitions for ventilator-associated pneumonia. Crit Care Med 2012;40:315461. doi:10.1097/CCM.0b013e318260c6d9.

[21] Klompas M, Branson R, Eichenwald EC, Greene LR, Howell MD, Lee G, et al. Strategies to Prevent Ventilator-Associated Pneumonia in Acute Care Hospitals: 2014 Update. Infect Control Hosp Epidemiol 2014;35:915-36. doi:10.1086/677144.

[22] Wallace FA, Alexander PDG, Spencer C, Naisbitt J, Moore JA, McGrath BA. A comparison of ventilator-associated pneumonia rates determined by different scoring systems in four intensive care units in the North West of England. Anaesthesia 2015;70:1274-80. doi:10.1111/anae.13211.

[23] Djuric O, Markovic-Denic L, Jovanovic B, Bumbasirevic V. Agreement between CDC/NHSN surveillance definitions and ECDC criteria in diagnosis of healthcare-associated infections in Serbian trauma patients. PLoS One 2018;13:e0204893. doi:10.1371/journal.pone.0204893.

[24] Craven TH, Wojcik G, McCoubrey J, Brooks O, Grant E, Reilly J, et al. Lack of concordance between ECDC and CDC systems for surveillance of ventilator associated pneumonia. Intensive Care Med 2017. doi:10.1007/s00134-017-4993-8.

[25] Food and Drug Administration X. Statistical Guidance on Reporting Results from Studies Evaluating Diagnostic Tests 2007.

[26] Suetens C, Morales I, Savey A, Palomar M, Hiesmayr M, Lepape A, et al. European surveillance of ICU-acquired infections (HELICS-ICU): methods and main results. J Hosp Infect 
2007;65 Suppl 2:171-3. doi:10.1016/S0195-6701(07)60038-3.

[27] Welsh Healthcare Associated Infection Programme. Surveillance: Central Venous Catheter (CVC) Infection and Ventilator Associated Pneumonia (VAP) in Critical Care 2012.

[28] Scottish Intensive Care Society Audit Group. Audit of Critical Care in Scotland 2016.

[29] Boyer AF, Schoenberg N, Babcock H, McMullen KM, Micek ST, Kollef MH. A Prospective Evaluation of Ventilator-Associated Conditions and Infection-Related Ventilator-Associated Conditions. Chest 2015;147:68-81. doi:10.1378/chest.14-0544.

[30] Klein Klouwenberg PMC, van Mourik MSM, Ong DSY, Horn J, Schultz MJ, Cremer OL, et al. Electronic implementation of a novel surveillance paradigm for ventilator-associated events. Feasibility and validation. Am J Respir Crit Care Med 2014;189:947-55. doi:10.1164/rccm.201307-13760C.

[31] Klompas M, Kleinman K, Murphy M V. Descriptive epidemiology and attributable morbidity of ventilator-associated events. Infect Control Hosp Epidemiol 2014;35:502-10. doi:10.1086/675834.

[32] Nussenblatt V, Avdic E, Berenholtz S, Daugherty E, Hadhazy E, Lipsett PA, et al. Ventilatorassociated pneumonia: overdiagnosis and treatment are common in medical and surgical intensive care units. Infect Control Hosp Epidemiol 2014;35:278-84. doi:10.1086/675279.

[33] Pugh R, Harrison W, Harris S, Roberts H, Scholey G, Szakmany T, et al. Is HELICS the Right Way? Lack of Chest Radiography Limits Ventilator-Associated Pneumonia Surveillance in Wales. Front Microbiol 2016;7:1271. doi:10.3389/fmicb.2016.01271. 
Figure 1. Flow chart of total admissions for the study period. CD: calendar day, MV: mechanically ventilated. 


\begin{tabular}{|l|l|}
\hline ECDC VAP & $\begin{array}{l}\text { VAP diagnosed by ECDC surveillance case definition (notably } \\
\text { requires chest radiology changes and can include negative cultures, } \\
\text { criteria across span of time; purpose - surveillance) }\end{array}$ \\
\hline CDC VAP & $\begin{array}{l}\text { VAP diagnosed by CDC surveillance criteria (notably requires } \\
\text { perturbation in oxygenation after period of stability, qualifying } \\
\text { antibiotic prescription, and positive microbiology; criteria across } \\
\text { span of time; purpose - surveillance) }\end{array}$ \\
\hline CS VAP & $\begin{array}{l}\text { Clinician suspected VAP: The initiation of a new antibiotic for } \\
\text { suspected chest infection in a ventilated patient after 2 CD of MV } \\
\text { which was not a "replacement" for a pre-existing antibiotic } \\
\text { prescription (does not mandate radiology or microbiology results; } \\
\text { made at a single point in time; purpose - real time empiric } \\
\text { management) }\end{array}$ \\
\hline
\end{tabular}

Table I - Brief overview of each study VAP definition. CD: Calendar day, MV: Mechanical Ventilation. 


\begin{tabular}{l|l|l} 
& Admitted $>2$ CD & Ventilated $>2 C D$ \\
(At-risk cohort)
\end{tabular}

Table II - Summary of enrolled cases and population at-risk for Ventilator-associated Pneumonia. CD: Calendar day (any part or whole day period from 0000hrs to 0000hrs). APACHE II: Acute physiology and chronic health evaluation. IQR: Interquartile range. 


\begin{tabular}{l|l|l|l|l} 
& Number & $\begin{array}{l}\text { Number } \\
\text { of events }\end{array}$ & $\begin{array}{l}\text { Events per } 1000 \\
\text { ventilation days } \\
\text { patients }\end{array}$ & $\begin{array}{l}\text { Proportion of at- } \\
\text { risk patients } \\
(\% \pm 95 \% \mathrm{Cl})\end{array}$ \\
\hline CDC VAP & 30 & 29 & $4.6(3.1-6.6)$ & $4.0(2.8-5.9)$ \\
ECDC VAP & 35 & 32 & $5.4(3.8-7.5)$ & $4.5(3.1-6.4)$ \\
CS VAP & 160 & 150 & $24.7(21.2-28.9)$ & $21.0(18.1-24.2)$
\end{tabular}

Table III - Rate of Ventilator-associated pneumonia diagnosis and proportion of at-risk patients. CDC VAP: Ventilator-associated pneumonia by CDC surveillance definition. ECDC VAP: Ventilator-associated pneumonia by ECDC surveillance definition. CS VAP: Clinician suspected ventilator-associated pneumonia. $\mathrm{Cl}$ : Confidence Interval. 


\begin{tabular}{|c|c|c|c|c|c|}
\hline & $\begin{array}{l}\text { Total at risk } \\
\text { cohort }\end{array}$ & CDC VAP & ECDC VAP & CS VAP & $p$ \\
\hline $\begin{array}{l}\text { Age } \\
\text { Median ( } \pm \mathrm{QQR})\end{array}$ & $\begin{array}{l}59 \\
(47.0-69.0)\end{array}$ & $\begin{array}{l}58.0 \\
(37.0-70.0)\end{array}$ & $\begin{array}{l}49.5 \\
(36.0-63.0)\end{array}$ & $\begin{array}{l}56.0 \\
(44.3-68.0)\end{array}$ & $0.1205^{a}$ \\
\hline $\begin{array}{l}\text { Male:Female } \\
\text { n (\%) }\end{array}$ & $\begin{array}{l}452: 261 \\
(63.4: 36.6)\end{array}$ & $\begin{array}{l}25: 4 \\
(86.2: 13.8)\end{array}$ & $\begin{array}{l}27: 5 \\
(84.4: 15.6)\end{array}$ & $\begin{array}{l}99: 51 \\
(66.0: 34.0)\end{array}$ & $0.0191^{b}$ \\
\hline $\begin{array}{l}\text { Apache score } \\
\text { Median ( } \pm I Q R)\end{array}$ & $\begin{array}{l}18 \\
(13-23)\end{array}$ & $\begin{array}{l}19 \\
(14.0-23.0)\end{array}$ & $\begin{array}{l}17 \\
(13.0-23.3)\end{array}$ & $\begin{array}{l}20 \\
(15.0-26.0)\end{array}$ & $0.2577^{\mathrm{a}}$ \\
\hline
\end{tabular}

Table IV - Baseline characteristics of each VAP cohort. ${ }^{a}$ Kruskal-Wallis test ${ }^{b}$ Chi-squared test. Statistical analyses do not include total at risk cohort values. CDC VAP: Ventilator-associated pneumonia by CDC surveillance definition. ECDC VAP: Ventilator-associated pneumonia by ECDC surveillance definition. CS VAP: Clinician suspected ventilator-associated pneumonia. IQR: Inter-quartile range. 


\section{ECDC VAP}

CDC VAP

\begin{tabular}{l|l|l|l} 
& + & - & \\
\hline+ & 5 & 24 & 29 \\
\hline- & 27 & 657 & 684 \\
\hline & 32 & 681 &
\end{tabular}

PPA

NPA
15.6

Kappa $\quad 0.127(-0.003$ to 0.256$)$

92.1

Table V - Concordance by patient between surveillance algorithms. Kappa: Cohen's Kappa ( $\pm 95 \%$ confidence intervals). PPA: Positive percent agreement. NPA: Negative percent agreement. CDC VAP: Ventilator-associated pneumonia by CDC surveillance definition. ECDC VAP: Ventilator-associated pneumonia by ECDC surveillance definition. 


\begin{tabular}{|c|c|c|c|}
\hline & PPA $(\%)$ & NPA (\%) & Kappa $( \pm 95 \% \mathrm{Cl})$ \\
\hline CS VAP and ECDC VAP & 53.1 & 80.5 & $0.122(0.050-0.193)$ \\
\hline CS VAP and CDC VAP & 58.6 & 80.6 & $0.131(0.059-0.202)$ \\
\hline
\end{tabular}

Table VI - Concordance amongst patients receiving novel antibiotic courses for suspected ventilator-associated pneumonia or surveillance VAP events. PPA: Positive percent agreement. NPA: Negative percent agreement. CDC VAP: Ventilator-associated pneumonia by CDC surveillance definition. ECDC VAP: Ventilator-associated pneumonia by ECDC surveillance definition. CS VAP: Clinician suspected ventilator-associated pneumonia. $\mathrm{Cl}$ : Confidence interval. 


\begin{tabular}{l|l|l|l|l} 
& $\begin{array}{l}\text { Number } \\
\text { of events }\end{array}$ & pumber of & $\begin{array}{l}\text { Events per } 1000 \\
\text { ventilation days }\end{array}$ & $\begin{array}{l}\text { Proportion of } \\
\text { at-risk patients } \\
( \pm 95 \% \mathrm{Cl})\end{array}$ \\
\hline VAE & 130 & 124 & $20.1(17.0-23.8)$ & $17.4(14.7-20.4)$ \\
\hline \hline VAC & 62 & 60 & $9.6(7.5-12.3)$ & $8.4(6.5-10.8)$ \\
IVAC & 38 & 38 & $5.7(4.3-8.1)$ & $5.3(3.9-7.3)$ \\
CDC VAP & 30 & 29 & $4.6(3.1-6.6)$ & $4.0(2.8-5.9)$
\end{tabular}

Table VII - Incidence of VAEs. VAE: Ventilator associated event. VAC: Ventilator-associated complication. IVAC: Infection related ventilator-associated complication. CDC VAP: Ventilatorassociated pneumonia by $\mathrm{CDC}$ surveillance definition. $\mathrm{Cl}$ : Confidence interval. 


\begin{tabular}{lll} 
& Reviewer 1 & Reviewer 2 \\
& $\%$ & $\%$ \\
\hline True VAP & 14.0 & 15.0 \\
Pulmonary oedema & 14.0 & 10.0 \\
Atelectasis & 21.0 & 17.0 \\
Deterioration of pre-existing condition & 27.0 & 29.0 \\
Inadequate microbiological data to draw & & \\
further conclusions & 14.0 & 7.0 \\
Other & 10.0 & 22.0
\end{tabular}

Table VIII - Alternative diagnoses (100 non VAP VAEs were assessed). VAP: Ventilator-associated pneumonia. VAE: Ventilator-associated event. 


\begin{tabular}{|c|c|c|}
\hline \multicolumn{2}{|c|}{ Criterion } & Feature \\
\hline \multicolumn{2}{|c|}{ Radiological } & $\begin{array}{l}\text { One or, in patients with underlying cardiac } \\
\text { or pulmonary disease, two chest x-rays or } \\
\text { CT scans with images suggestive of } \\
\text { pneumonia. }\end{array}$ \\
\hline \multicolumn{2}{|c|}{ Systemic. At least one of: } & $\begin{array}{l}\text { Fever }\left(>38^{\circ} \mathrm{C}\right) \\
\text { Leukopaenia }\left(<4 \times 10^{9} / \mathrm{L} \text { white cell count) or }\right. \\
\text { leukocytosis ( } \geq 12 \times 10^{9} / \mathrm{L} \text { white cell count) }\end{array}$ \\
\hline \multicolumn{2}{|c|}{$\begin{array}{l}\text { Pulmonary. At least one of, or in the } \\
\text { absence of supportive microbiological data, } \\
\text { at least two of: }\end{array}$} & $\begin{array}{l}\text { New onset of purulent sputum or change in } \\
\text { character of sputum. } \\
\text { Worsening gas exchange. } \\
\text { Cough, or dyspnoea, or tachypnea } \\
\text { Suggestive auscultation }\end{array}$ \\
\hline \multicolumn{3}{|c|}{$\begin{array}{l}\text { An ICU-acquired infection is one that occurs after } 48 \mathrm{hrs} \text { in ICU. For intubation-associated } \\
\text { pneumonia, an invasive respiratory device must have been present for at least part of the } \\
\text { preceding } 48 \mathrm{hrs.}\end{array}$} \\
\hline \multicolumn{3}{|c|}{ Microbiological category } \\
\hline PN1 & \multicolumn{2}{|c|}{$\begin{array}{l}\text { Minimally contaminated lower respiratory tract sample with } \\
\text { quantitative culture }\left(10^{4} \mathrm{CFU} / \mathrm{ml} \text { for broncho-alveolar lavage, } 10\right. \\
\text { CFU/ml for protected brush samples or distal protected aspirate })\end{array}$} \\
\hline PN2 & \multicolumn{2}{|c|}{$\begin{array}{l}\text { Non-protected sample (endotracheal aspirate, ETA) with quantitative } \\
\text { culture }\left(10^{6} \mathrm{CFU} / \mathrm{ml}\right)\end{array}$} \\
\hline PN3 & \multicolumn{2}{|c|}{ Alternative microbiological criteria (e.g. positive blood culture) } \\
\hline PN4 & \multicolumn{2}{|c|}{ Sputum bacteriology or non-quantitative ETA } \\
\hline PN5 & \multicolumn{2}{|c|}{ No microbiological documentation } \\
\hline
\end{tabular}

Supplemental Table I - ECDC criteria for ventilator-associated pneumonia. PN = Pneumonia. Adapted from Pugh et al.[33] 


\begin{tabular}{|c|c|c|c|}
\hline & CDC VAP & ECDC VAP & CS VAP \\
\hline Organism & \multicolumn{3}{|c|}{$\mathrm{n}$ (\% of VAP cases) } \\
\hline No organism & $0(0)$ & $17(48.5)$ & $129(80.6)$ \\
\hline MSSA & $11(36.7)$ & $6(17.1)$ & $13(8.1)$ \\
\hline Streptococcus pneumoniae & $2(6.7)$ & $2(5.7)$ & $3(1.9)$ \\
\hline Enterococcus faecalis & $0(0)$ & $1(2.9)$ & $0(0)$ \\
\hline Corynebacterium striatum & $0(0)$ & $1(2.9)$ & $0(0)$ \\
\hline Haemophilus influenzae & $5(16.7)$ & $5(14.3)$ & $2(1.3)$ \\
\hline Moraxella catarrhalis & $1(3.3)$ & $0(0)$ & $1(0.6)$ \\
\hline Escherichia coli & $3(10.0)$ & $1(2.9)$ & $6(3.8)$ \\
\hline Proteus mirabilis & $3(10.0)$ & 0 & $2(1.3)$ \\
\hline Proteus vulgaris & $0(0)$ & $1(2.9)$ & $0(0)$ \\
\hline Klebsiella pneumonia & $6(20.0)$ & $0(0)$ & $0(0)$ \\
\hline Klebsiella oxytoca & $2(6.7)$ & $0(0)$ & $3(1.9)$ \\
\hline Raoultella ornithinolytica & $1(3.3)$ & $0(0)$ & $0(0)$ \\
\hline Raoultella planticola & $0(0)$ & $0(0)$ & $1(0.6)$ \\
\hline Serratia marcescens & $1(3.3)$ & $1(2.9)$ & $1(0.6)$ \\
\hline Citrobacter koseri & $1(2.5)$ & $0(0)$ & $2(1.3)$ \\
\hline Morganella morganii & $0(0)$ & $0(0)$ & $1(0.6)$ \\
\hline Enterobacter aerogenes & $1(3.3)$ & $2(5.7)$ & $1(0.6)$ \\
\hline Enterobacter cloacae & $0(0)$ & $2(5.7)$ & $0(0)$ \\
\hline Acinetobacter ursingii & $1(3.3)$ & $1(2.9)$ & $1(0.6)$ \\
\hline Pseudomonas aeruginosa & $1(3.3)$ & $0(0)$ & $1(0.6)$ \\
\hline $\begin{array}{l}\text { Stenotrophomonas } \\
\text { maltophilia }\end{array}$ & $0(0)$ & $0(0)$ & $1(0.6)$ \\
\hline Influenza B & $1(3.3)$ & $0(0)$ & $0(0)$ \\
\hline
\end{tabular}

MSSA: Meticillin sensitive Staphylococcus aureus.

Supplemental table II - Microbiology of VAP. Individual VAP events may have had more than one discernible causative organism. Laboratory identifications were by Bruker Maldi-ToF and sensitivity testing by EUCAST methodology. CDC VAP: Ventilator-associated pneumonia by CDC surveillance definition. ECDC VAP: Ventilator-associated pneumonia by ECDC surveillance definition. CS VAP: Clinician suspected ventilator-associated pneumonia. 
CS VAP

\begin{tabular}{|c|c|c|c|}
\hline \multicolumn{4}{|c|}{ ECDC VAP } \\
\hline & + & - & \\
\hline+ & 17 & 133 & 150 \\
\hline - & 15 & 548 & 563 \\
\hline & 32 & 681 & \\
\hline
\end{tabular}

PPA

NPA

53.1

80.5

Kappa $0.122(0.050-0.193)$

\begin{tabular}{l|l|l|l}
\multicolumn{5}{c}{ CDC VAP } \\
& + & - & \\
\hline+ & 17 & 133 & 150 \\
\hline- & 12 & 551 & 563 \\
\hline & 29 & 684 &
\end{tabular}

PPA

NPA

58.6

80.6

Карра $0.131(0.059-0.202)$

\begin{tabular}{l|l|l|l}
\multicolumn{5}{c}{ ECDC VAP } \\
& + & - & \\
\hline+ & 7 & 27 & 34 \\
\hline- & 25 & 654 & 679 \\
\hline & 32 & 681 &
\end{tabular}

PPA

NPA

21.9

96.0

Kappa $0.174(0.038-0.310)$

CS VAPm

\begin{tabular}{l|l|l|l}
\multicolumn{4}{c}{ CDC VAP } \\
& + & - & \\
\hline+ & 14 & 20 & 34 \\
\hline- & 15 & 664 & 679 \\
\hline & 29 & 684 &
\end{tabular}

PPA

NPA

48.3

97.1

Kappa $0.419(0.261-0.576)$

Supplemental table III - Concordance amongst patients receiving novel antibiotic courses for suspected ventilator-associated pneumonia (CS VAP) or surveillance VAP events. CS VAPm: CS VAP where microbiological samples were sent for analysis with 5 calendar days of the initiation of antibiotics. There is no perfect reference standard amongst the available data so concordance is expressed as positive percent agreement (PPA, analogous to sensitivity if a perfect reference standard were available) and negative percent agreement (NPA, analogous to specificity if a perfect reference standard were available) [25]. Kappa: Cohen's Kappa ( $\pm 95 \%$ confidence intervals). CDC VAP: Ventilator-associated pneumonia by CDC surveillance 
definition. ECDC VAP: Ventilator-associated pneumonia by ECDC surveillance definition. CS VAP: Clinician suspected ventilator-associated pneumonia. 
Reviewer 1

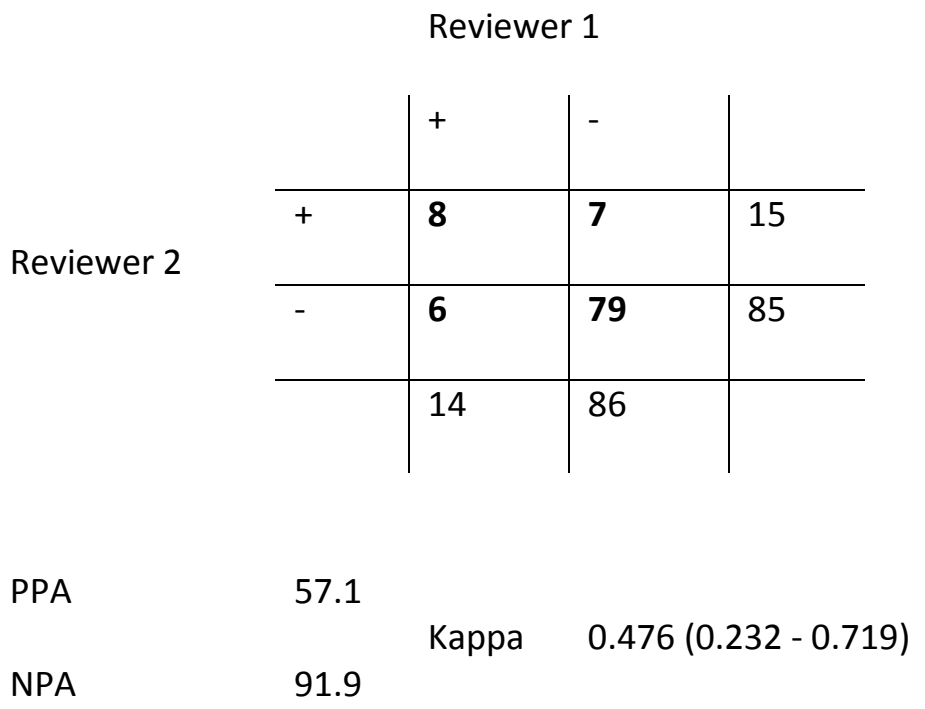

Supplemental Table IV - Concordance between independent reviewers for True VAP diagnoses. PPA:

Positive percent agreement. NPA: Negative percent agreement. Kappa: Cohen's Kappa. 
$\geq 2$ calendar days stability or improvement followed by sustained deterioration ( $\geq 2$ calendar days) - defined by daily minimum PEEP and $\mathrm{FiO}_{2}$.

Therefore the first day of deterioration cannot occur before the $3^{\text {rd }}$ calendar of admission

Ventilator-associated condition (VAC)

The first day of deterioration defines the centre of a 5 day "IVAC window", during which subsequent criteria must be met. NB The IVAC window cannot extend before the $3^{\text {rd }}$ calendar of admission.

During IVAC window

1) Temperature $>38^{\circ} \mathrm{C}$ or $<36^{\circ} \mathrm{C}$, OR white cell count $\geq 12,000$ cells $/ \mathrm{mm}^{3}$ or $\leq 4,000$ cells $/ \mathrm{mm}^{3}$

2) AND

3) 2) A new eligible microbiological agent is started, and is continued for $\geq 4$ calendar days

Infection-related ventilator-associated condition (IVAC)

During the IVAC window ONE of the following criteria is met:

1) One of:

- Endotracheal aspirate, $\geq 105 \mathrm{CFU} / \mathrm{ml}$ or corresponding semi-quantitative result

- Broncho-alveolar lavage, $\geq 104 \mathrm{CFU} / \mathrm{ml}$ or corresponding semi-quantitative result

- Lung tissue, $\geq 104 \mathrm{CFU/g}$ or corresponding semi-quantitative result

- Protected specimen brush, $\geq 103 \mathrm{CFU} / \mathrm{ml}$ or corresponding semi-quantitative result

2) Purulent respiratory secretions AND plus organism identified from one of the following specimens (not meeting quantitative thresholds outlined in criterion 1.

- Sputum

- Endotracheal aspirate

- Broncho-alveolar lavage

- Lung tissue

- Protected specimen brush

3) One of:

- Organism identified from pleural fluid

- Lung histopathology supportive of diagnosis

- Diagnostic test for Legionella species

- Diagnostic test on respiratory secretions eligible viral infections

Possible ventilator-associated pneumonia (PVAP)

\section{Supplemental Figure 1 - An overview of hierarchical diagnosis of ventilator-associated events}

(January 2015, updated April 2015). Adapted from https://www.cdc.gov/nhsn/acute-carehospital/vae/index.html. 


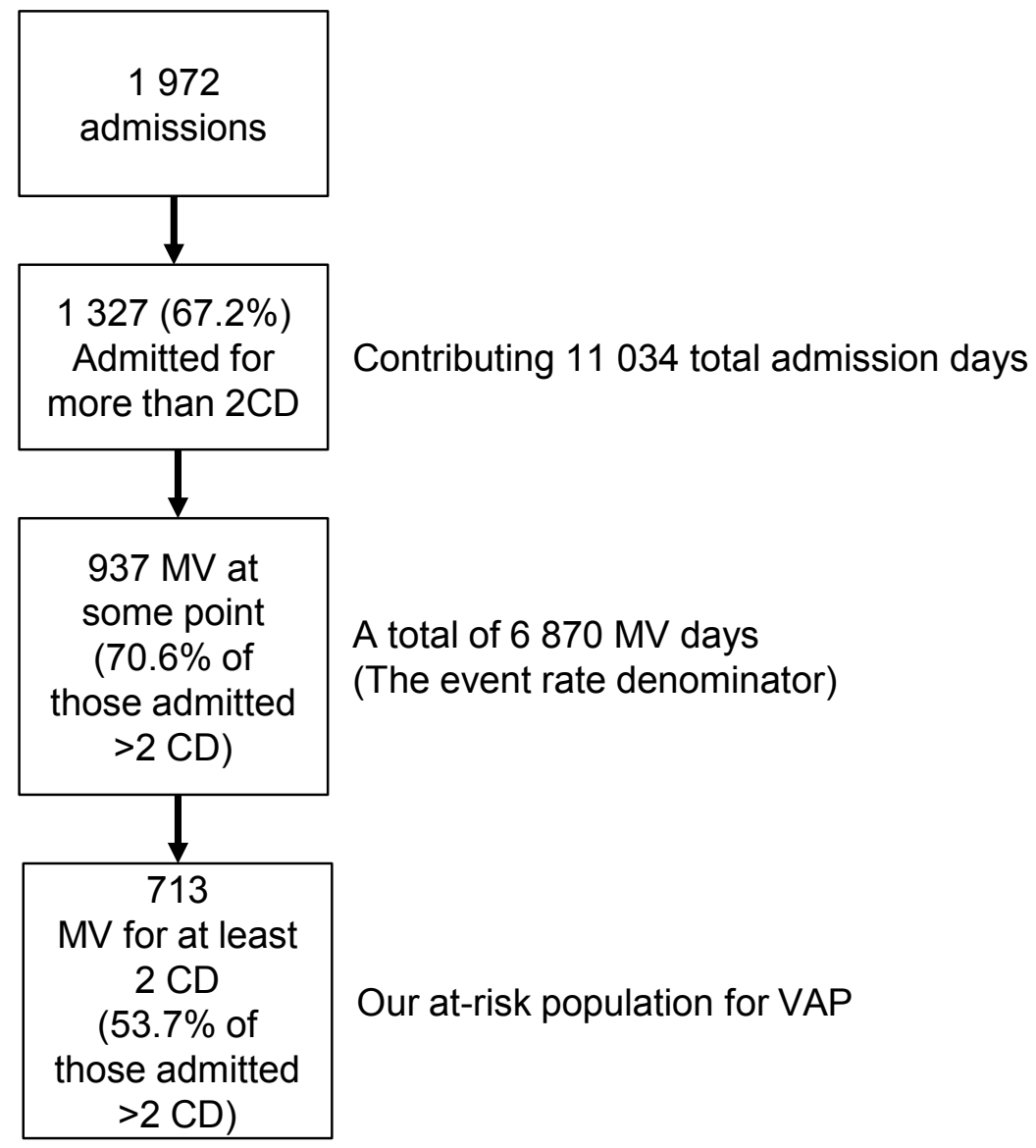

